\title{
Prognostic factors in patients operated for intracerebral hematoma
}

\author{
(1) Alparslan Kırık, (1) Soner Yaşar \\ University of Health Sciences Turkey, Gülhane Training and Research Hospital, Clinic of Neurosurgery, Ankara, Turkey
}

Date submitted:

18.11.2019

Date accepted:

16.12.2019

Online publication date: 15.06.2020

\section{Corresponding Author:}

Alparslan Kırık MD, University of Health Sciences Turkey, Gülhane Training and Research Hospital, Clinic of Neurosurgery, Ankara, Turkey dr_alper@hotmail.com

ORCID:

orcid.org/0000-0002-8160-6199

Keywords: Intracerebral hemorrhage, hemorrhage volume, prognosis, surgery

\begin{abstract}
Aims: Intracerebral hemorrhages $(\mathrm{ICH})$ are usually seen in patients with stroke. In this pathology; $\mathrm{ICH}$ volume, location of the hemorrhage and hemorrhage expanding into the ventricular system are the main factors affecting the mortality respectively. Increase in ICH volume often results in neurological deterioration. Our aim is to determine the prognostic factors in patients who underwent surgical treatment for $\mathrm{ICH}$.

Methods: We retrospectively evaluated 52 patients operated in our department due to ICH which occurred spontaneously or were caused by the other etiological factors between 2017 and 2019. The parameters were the Glasgow Coma Scale (GCS) score, ICH volume in computed tomography scan, and ventricular expansion of the hemorrhage.
\end{abstract}

Results: The mortality rate in our series was $61.5 \%$. Mortality was significantly increased in patients with hematoma larger than $60 \mathrm{~cm}^{3}$. Nineteen of $24(46 \%)$ patients with GCS scores between 3 and 8 died in the postoperative period. The mean duration of hospital stay was 33 days. $73 \%$ of the hematomas were seen in the lobar region.

Conclusions: Low GCS score at admission and high ICH volume are prognostic factors for patients who have undergone surgery for $\mathrm{ICH}$.

\section{Introduction}

Primary intracerebral hemorrhage $(\mathrm{ICH})$ is a vascular disease of the brain, caused by hemorrhage into the brain parenchymal tissue (cerebrum, cerebellum, brain stem). $\mathrm{ICH}$ account for $12 \%$ of all strokes (1). In the other studies, this ratio also counts for $8-18 \%(2,3)$. Short-term outcome of patients with $\mathrm{ICH}$ is very poor; about half of these patients die within 30 days $(4,5)$. In these patients, early survival is associated with present state of consciousness, hematoma volume, and the existence of intraventricular hemorrhage $(6,7)$. The annual incidence of $\mathrm{ICH}$ is $30.9 / 100.000$ in the USA and $52 / 100.000$ in Japan (8).

Advanced age, hypertension, alcohol and tobacco usage, the presence of ischemic stroke history and anticoagulant use are the accepted risk factors for $\mathrm{ICH}$ (9). Despite the improvements in the treatment of hypertension and a decrease in the frequency of $\mathrm{ICH}$, the overall incidence did not change because of increase in bleeding due to antithrombotics and cerebral amyloid angiopathy (CAA) in elder people $(10,11)$.

In the sixth month after the acute event, only $20 \%$ of patients can function independently in daily life and more than $50 \%$ are lost in the first year $(12,13)$. Acute $\mathrm{ICH}$ treatment is a multidisciplinary effort that requires close collaboration among doctors, nurses and technicians working in neurology, neurosurgery, radiology, intensive care and emergency medicine.

Clinical features of $\mathrm{ICH}$ depend on the location, size, enlargement, presence of intraventricular blood and associated medical problems. Cognitive disturbances, hemiparesis/ hemiplegia, visual dysfunctions, cranial nerve deficits, sensory deficits, gait and coordination problems may occur as neurological deficits. Clinical deterioration in $\mathrm{ICH}$ is more rapid than in ischemic stroke. Moreover, nausea, vomiting and 
headache are more frequent in patients with $\mathrm{ICH}$ (14). Distortion occurs in the state of consciousness earlier; this is more common in massive hemorrhages, obstructing ventricular flow leading to hydrocephalus, and brain stem hemorrhage (15).

Diagnosis is mainly based on the detection of hyperdense hemorrhage in the brain tissue and/or ventricles on computed brain tomography (CT). Radiological imaging not only shows $\mathrm{ICH}$ but also reveals the cause of hemorrhage. A management plan is prepared based on some characteristics such as the site of bleeding, age of patient, and risk factors. The patient may be expected to become clinically stable for diagnostic imaging, unless the presence of a lesion requiring an intervention in the acute period, such as aneurysm, is suspected. The presence of hypertension and the location of the bleeding are the most important factors in understanding the underlying pathology.

In patients presenting with deep location (putamen, head of the caudate nucleus, thalamus, pons, cerebellum) bleeding, the etiology is usually hypertension. In patients presenting with more superficial (lobar) bleeding, it is necessary to obtain brain magnetic resonance imaging (MRI) including FLAIR, weighted gradient echo or susceptibility weighted imaging and non-contrast/contrastenhanced T1-weighted sequences to exclude other underlying pathologies (tumors, vascular pathologies, and infections).

In patients with ischemic stroke, diffusion-weighted imaging and magnetic resonance venography combined with clinical findings may be used for the recognition of hemorrhage within the infarction region. Although non-invasive techniques such as magnetic resonance angiography (MRA) and CT angiography (CTA) are widely used in the detection of vascular pathologies including arteriovenous malformation (AVM) and aneurysm, catheter-based cerebral angiography is still the ultimate research method. In general, the detection of an underlying lesion by vascular imaging is easier in patients younger than 45 years-old and without hypertension (16). Although the use of these methods differs even in developed centers, it is an ideal approach to investigate vascular pathology in all patients with $\mathrm{ICH}$ at least with a non-invasive method such as MRA or CTA.

\section{Methods}

This retrospective study was approved by Gülhane NonInterventional Ethics Committee (number: 19/311, date: 08.10.2019).

\section{Patients}

We retrospectively reviewed the data of 52 patients who underwent surgery for ICH between 2017 and 2019. Twentyseven (52\%) patients were male and 25 (48\%) were female. The youngest patient was six months old and the oldest was 89 years old (mean age $=62$ years). Most of the bleedings were spontaneous in our series. In addition, other etiological factors were as follows; trauma, iatrogenic, vascular diseases, gunshot injuries, coagulation disorders, etc. (Table 1). $63.4 \%(n=33)$ of patients were given anticoagulant or antiaggregant treatment for different reasons. Bleeding into the ventricles was observed in $35(67.3 \%)$ of the cases. When the bleeding was evaluated according to location, it was most commonly seen in the lobar region. Other locations were Thalamus, Putamen, Parafalcian region, Cerebellum etc. (Table 2) (Figure 1, 2).

\section{Evaluation and surgical procedure}

All patients were examined by non-contrast CT scan at admission according to the severity of neurological status. CTA and/or MRI was performed when vascular pathology was

\begin{tabular}{lll}
$\begin{array}{l}\text { Table 1. Distribution of cases } \\
\text { factors }\end{array}$ & Number & Frequency (\%) \\
\hline Etiology & 31 & 59.6 \\
\hline Spontaneous & 10 & 19.2 \\
\hline Trauma & 4 & 7.6 \\
\hline latrogenic & 4 & 7.6 \\
\hline $\begin{array}{l}\text { Vascular diseases (AVM, } \\
\text { aneurysm) }\end{array}$ & 3 & 5.7 \\
\hline Others (TPA usage etc.) & 3 & \\
\hline AVM: Arteriovenous malformation & & \\
\hline
\end{tabular}

Table 2. Frequency of hematomas according to anatomical location

\begin{tabular}{lll}
\hline Hematoma location & Number & Frequency (\%) \\
\hline Lobar & 38 & 73 \\
\hline Thalamic & 6 & 11.5 \\
\hline Putaminal & 3 & 5.7 \\
\hline Cerebellar & 3 & 5.7 \\
\hline Parafalcine & 2 & 3.8 \\
\hline
\end{tabular}

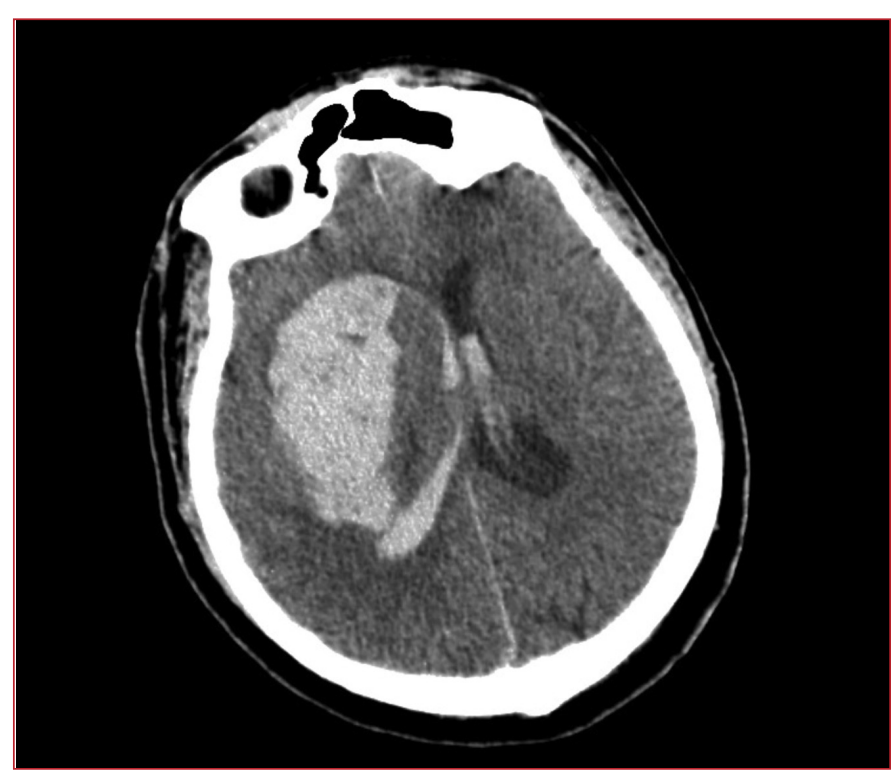

Figure 1. Computed tomography scan of a patient with acute left putaminal intracerebral hemorrhages opened to the lateral ventricle 
suspected according to the location of $\mathrm{ICH}$ and risk factors of the patient. The patients underwent general and neurological evaluation as soon as they were first seen in the emergency department.

The patients were evaluated according to the Glasgow Coma Scale (GCS) at the first neurological examination. Hematoma volume in patients can be determined by simple, validated $A \times B$ x C / 2 formula on brain tomography (A: the largest diameter of the hemorrhage, $B$ : the largest bleeding diameter perpendicular to $A$ in the same section, $C$ : multiplying of the number of sections and section thickness of the bleeding).

Antihypertensive agents suitable for blood pressure regulation were started. Vitamin $\mathrm{K}$ and Fresh Frozen Plasma (FFP) supplementation was provided in the patients using coumadin. Erythrocyte suspension and FFP were prepared before the operation. Basic interventions such as raising the head, using analgesics and lowering the body temperature were performed to reduce intracranial pressure. All patients were operated under general anesthesia. Craniotomy and endoscopic removal were used as a surgical technique in all cases.

\section{Results}

The smallest hematoma volume was $6 \mathrm{~cm}^{3}$ and the largest hematoma volume was $205 \mathrm{~cm}^{3}$. When our cases were evaluated, we found that mortality was significantly increased in cases with hematoma greater than $60 \mathrm{~cm}^{3}$ (Table 3). The duration of hospital stay was at least 1 day and at most 195 days with the mean hospital stay that was 33 days. In two of the cases, burr holes were used for hematoma evacuation; on the other hand, in all other cases, craniotomy of various sizes was performed initially. In patients who underwent craniotomy, bone flap was not placed in 9 patients after the evacuation of

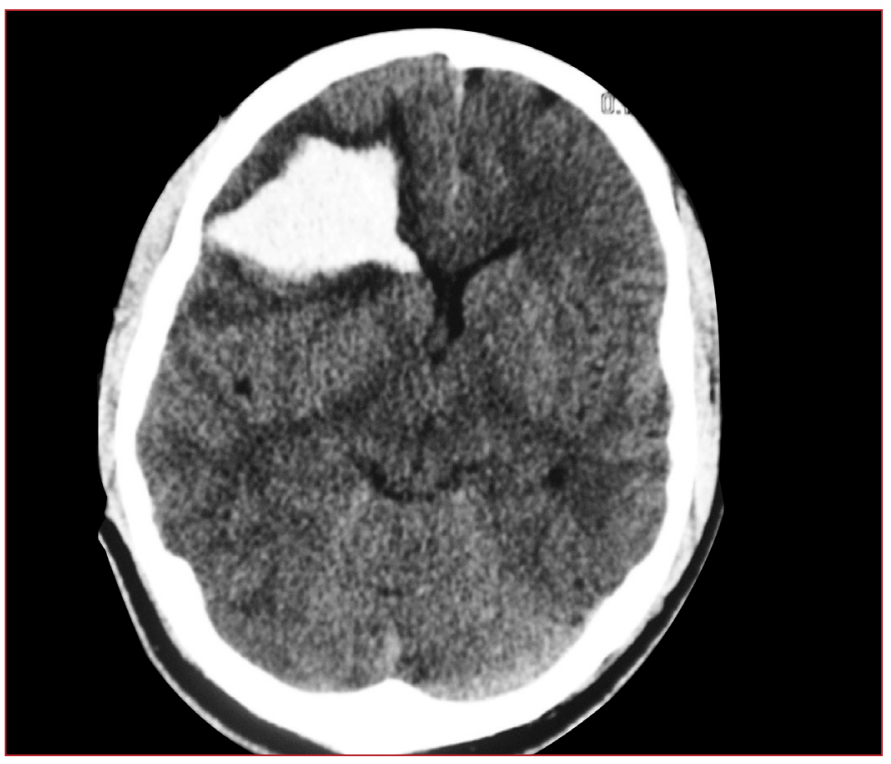

Figure 2. Computed tomography scan of a patient with acute lobar (left frontal) intracerebral hemorrhages the hematoma due to brain swelling. In 6 of the cases, only external ventricular drainage (EVD) was inserted for the relief of intracranial hypertension. In addition, EVD was inserted in 3 of the other patients who underwent craniotomy for the evacuation of the hematoma. Considering the location and nature of bleeding, additional CTA revealed middle cerebral artery aneurysm in 3 patients and AVM in 1 patient. In these patients, in addition to hematoma evacuation, primary vascular pathology was treated. In 2 cases, hematoma was evacuated endoscopically.

\section{Discussion}

Spontaneous $\mathrm{ICH}$ constitutes the majority of bleeding in the brain parenchyma. In our clinical study, 31 (59.6\%) patients had spontaneous $\mathrm{ICH}$. Van Asch et al. (17), in a review of $\mathrm{ICHs}$, especially between the ages of 45 and 54 years, 85 years and older than seen more, there is no gender difference in mortality due to $\mathrm{ICH}$. The incidence of $\mathrm{ICH}$ is $25 / 100.000$, The highest rate is in Asians (51.8/100.000) and the lowest is in the Spaniards (19.6/100.000). In our clinical study, the majority $(76.9 \%)$ of the cases were between the ages of 50 and 80 years. The male/ female ratio was 1.08 .

The main causes of spontaneous $\mathrm{ICH}$ are hypertension, CAA, vascular diseases, and coagulopathies $(18,19)$. Eighteen of our cases were found to be using anticoagulants or antiaggregants for the treatment of their primary pathologies. Among them, the most important risk factors were older age, acute or chronic hypertension. Cheung and Zou (20) emphasized that $72-81 \%$ of patients with $\mathrm{ICH}$ were hypertensive. Ruiz-Sandoval et al. (21) found the most frequent underlying factor of $\mathrm{ICH}$ as hypertension (69\%) and then obesity. Forty-one $(78.8 \%)$ of our patients had a history of hypertension and 24 (75\%) of these patients with hypertension died in the postoperative period. The etiological factors in our clinical series for non-spontaneous ICH are shown in Table 1.

Mortality rate in $\mathrm{ICH}$ is much higher than in other stroke types (19). To date, many studies have been conducted in the literature on surgical indications and treatment outcomes of ICHs $(22,23)$. The main purpose of surgical management is the prevention of death and the second purpose is to lower the risk of neurological sequelae. Except for superficial lobar $\mathrm{ICH}$, the superiority of surgery has not been demonstrated in deeply localized spontaneous ICHs $(17,24)$. The aim of our surgical

\begin{tabular}{llll}
\hline $\begin{array}{l}\text { Table 3. Relationship between hematoma } \\
\text { prognosis }\end{array}$ & $\begin{array}{l}\text { Died } \\
(\mathbf{n = 3 2})\end{array}$ & $\begin{array}{l}\text { Alive } \\
(\mathbf{n}=\mathbf{2 0})\end{array}$ & $\begin{array}{l}\text { Total } \\
(\mathbf{n}=\mathbf{5 2})\end{array}$ \\
\hline Hematoma volume & 0 & 2 & 2 \\
\hline$<10 \mathrm{~cm}^{3}$ & 7 & 9 & 16 \\
\hline $10-30 \mathrm{~cm}^{3}$ & 9 & 3 & 12 \\
\hline $30-60 \mathrm{~cm}^{3}$ & 16 & 6 & 22 \\
\hline$>60 \mathrm{~cm}^{3}$ & & & \\
\hline
\end{tabular}


treatment in $\mathrm{ICH}$ is to eliminate the mass effect of hematoma, to prevent secondary brain stem compression, to decrease intracranial hypertension and to shorten the recovery time. In terms of prognosis, initial consciousness of the patients, size and localization of the hematoma and ventricular spreading are important factors $(20,25)$. The group with the best prognosis according to location is lobar hematomas (20).

GCS was evaluated during the patient's admission at hospital and 19 of 24 (46\%) patients having scores between 3 and 8 died in the postoperative period. High mortality rate was mostly associated with low GCS score.

Early surgical intervention was performed following the evaluation of the patients. It was evaluated that early intervention had a positive effect on the survival of patients having low GCS and ventricular bleeding. Mendelow and Unterberg (26) have shown that early surgery is associated with better prognosis in lobar hemorrhages. However, in another study, drainage of lobar hematomas larger than $20 \mathrm{~mL}$ and deep ICHs by craniotomy within the first 4 hours after the onset of complaints increased the risk of bleeding and therefore, the study was terminated early (27).

Currently, indications for early surgical intervention are lifethreatening lobar hemorrhages and cerebellar hemorrhage with the largest diameter above $3 \mathrm{~cm}$ (28). Surgical intervention can be performed with open craniotomy or stereotactic approaches in the case of clinical or radiological deterioration in any $\mathrm{ICH}$ patient with an acceptable prognosis.

The prognosis of severe brain stem hemorrhage and massive dominant hemisphere hemorrhage is generally very poor. The placement of EVD during surgery or alone allows both the measurement of intracranial pressure and the treatment of cerebrospinal fluid drainage. Only 6 of our patients underwent EVD application and 5 of these patients recovered with benefit from treatment.

In the literature, different rates of bleeding location have been reported, and putaminal hematomas constitute the most common group with a rate of $34 \%$, followed by lobar and thalamic hematomas in order of frequency (29). In our case series, $73 \%$ of the hematomas were seen in the lobar region and $11.5 \%$ in the thalamic region (Table 2).

Low GCS score at admission (<8), advanced age, infratentorial location, high $\mathrm{ICH}$ volume and intraventricular hemorrhage were found to be independently associated with poor prognosis (30). Hematoma volume and ventricular hematoma are the most important determinants of mortality associated with $\mathrm{ICH}(6,7)$. ICH volume is a very important prognostic indicator. In a CT-based study, only one of 71 patients with parenchymal bleeding greater than $30 \mathrm{~cm}^{3}$ was able to live independently in daily life after 30 days following the acute event (7). In our cases, as shown in Table 3, only 6 of 22 cases with more than $60 \mathrm{~cm}^{3}$ survived.
In another study performed by Garde et al. (25) based on CT scan, ventricular opening rate was found to be $43 \%$ and it was more frequent especially in central and thalamic hematomas. Thirty-five (67.3\%) of our $\mathrm{ICH}$ cases were found to open to any ventricle (lateral ventricle, third ventricle, fourth ventricle) and this rate was high compared to the literature.

Long-term mortality rates for $\mathrm{ICH}$ have not been reported in most of the previous studies. One-month mortality rate in spontaneous $\mathrm{ICH}$ was reported as $34.4 \%$ by Nakayama et al. (31). In another investigation by Karnik et al. (24), one-month mortality rate was $37.1 \%$ and annual mortality rate was $49.6 \%$. In the study of Kanaya (32) published in 5255 cases, which is the largest series ever published, $22 \%$ postoperative mortality has been reported. Kaneko et al. (29) published 7 mortality cases in 100 patients who they operated urgently.

In our series, we evaluated that hematomas opening to ventricles and hematomas larger than $60 \mathrm{~cm}^{3}$ in general increased mortality significantly. In addition, GCS score was significant in terms of prognosis at admission.

\section{Conclusion}

Initial low GCS score and large hematoma volume are poor prognostic factors in patients who have undergone surgery for $\mathrm{ICH}$.

\section{Ethics}

Ethics Committee Approval: This retrospective study was approved by Gülhane Non-Interventional Ethics Committee (number: 19/311, date: 08.10.2019).

Informed Consent: Retrospective study.

Peer-review: Externally peer-reviewed.

\section{Authorship Contributions}

Concept: A.K., S.Y., Design: A.K., Data Collection or Processing: A.K., S.Y., Analysis or Interpretation: A.K., S.Y., Literature Search: A.K., S.Y., Writing: A.K., S.Y.

Conflict of Interest: No conflict of interest was declared by the authors.

Financial Disclosure: The authors declared that this study received no financial support.

\section{References}

1. Keir SL, Wardlaw JM, Warlow CP. Stroke epidemiology studies have underestimated the frequency of intracerebral haemorrhage. A systematic review of imaging in epidemiological studies. J Neurol. 2002;249:1226-1231.

2. Bornstein NM, Aranowich BD, Karepov VG, et al. The Tel Aviv Stroke Registry: 3600 Consecutive Patients. Stroke. 1996;27:1770-1773. 
3. Massaro AR, Sacco RL, Mohr JP, et al. Clinical discriminators of lobar and deep hemorrhages: the Stroke Data Bank. Neurology. 1991;41:1881-1885.

4. Bamford J, Sandercock P, Dennis M, Burn J, Warlow C. A prospective study of acute cerebrovascular disease in the community: the Oxfordshire Community Stroke Project--1981-86. 2. Incidence, case fatality rates and overall outcome at one year of cerebral infarction, primary intracerebral and subarachnoid haemorrhage. J Neurol Neurosurg Psychiatry. 1990;53:16-22.

5. Thrift AG, Dewey HM, Macdonell RA, McNeil JJ, Donnan GA. Incidence of the major stroke subtypes: initial findings from the North East Melbourne stroke incidence study (NEMESIS). Stroke. 2001;32:1732-1738.

6. Inagawa T, Ohbayashi N, Takechi A, Shibukawa M, Yahara K. Primary intracerebral hemorrhage in Izumo City, Japan: incidence rates and outcome in relation to the site of hemorrhage. Neurosurgery. 2003;53:1283-1298.

7. Broderick JP, Brott TG, Duldner JE, Tomsick T, Huster G. Volume of intracerebral hemorrhage. A powerful and easy-touse predictor of 30-day mortality. Stroke. 1993;24:987-993.

8. Inagawa T. Risk factors for primary intracerebral hemorrhage in patients in Izumo City, Japan. Neurosurg Rev. 2007;30:225-234.

9. Smith EE, Koroshetz WJ. Epidemiology of Stroke. In: Furie KL, Kelly PJ, editor). Current Clinical Neurology. Handbook of stroke prevention in clinical practice. Totowa N.J: Humana Press; 2004:1-1.

10. Lovelock CE, Molyneux AJ, Rothwell PM; Oxford Vascular Study. Change in incidence and aetiology of intracerebral haemorrhage in Oxfordshire, UK, between 1981 and 2006: a population-based study. Lancet Neurol. 2007;6:487493.

11. Flaherty $\mathrm{ML}$, Kissela $\mathrm{B}$, Woo $\mathrm{D}$, et al. The increasing incidence of anticoagulant-associated intracerebral hemorrhage. Neurology. 2007;68:116-121.

12. Broderick JP, Adams HP Jr, Barsan W, et al. Guidelines for the management of spontaneous intracerebral hemorrhage: A statement for healthcare professionals from a special writing group of the Stroke Council, American Heart Association. Stroke. 1999;30:905-915.

13. Flaherty $\mathrm{ML}$, Haverbusch $\mathrm{M}$, Sekar $\mathrm{P}$, et al. Long-term mortality after intracerebral hemorrhage. Neurology. 2006;66:1182-1186.

14. Adams HP. Clinical manifestations of ischemic stroke. In: Adams HP, editor. Principles of cerebrovascular disease. New York: McGraw-Hill Medical; 2007:91-116.

15. Adam HP. Clinical manifestations of hemorrhagic stroke. In: Adams HP, editor. Principles of cerebrovascular disease. New York: McGraw-Hill Medical; 2007:117-130.

16. Zhu XL, Chan MS, Poon WS. Spontaneous intracranial hemorrhage: which patients need diagnostic cerebral angiography? A prospective study of 206 cases and review of the literature. Stroke. 1997;28:1406-1409.
17. van Asch CJ, Luitse MJ, Rinkel GJ, van der Tweel I, Algra A, Klijn CJ. Incidence, case fatality, and functional outcome of intracerebral haemorrhage over time, according to age, sex, and ethnic origin: A systematic review and metaanalysis. Lancet Neurol. 2010;9:167-176.

18. Bakır A, Yılmaz R, Sarılar C, Tuna H, Cağlar S. İntraserebral hematomlar. Turk Norosir Derg. 2006;16:42-44.

19. Kase CS, Robinson RK, Stein RW, et al. Anticoagulant-related intracerebral hemorrhage. Neurology. 1985;35:943-948.

20. Cheung RT, Zou LY. Use of the original, modified or new intracerebral hemorrhage score to predict mortality and morbidity after intracerebral hemorrhage. Stroke. 2003;34:1717-1722.

21. Ruiz-Sandoval JL, Ortega-Alvarez L, García-Navarro V, Romero Vargas S, González-Cornejo S. Intracerebral haemorrhage in a referral hospital in the central-western region of Mexico. Rev Neurol. 2005;40:656-660.

22. Broderick JP. Advances in the treatment of hemorrhagic stroke: A possible new treatment. Cleve Clin J Med. 2005;72:341-344.

23. Siddique MS, Mendelow AD. Surgical treatment of intracerebral haemorrhage. Br Med Bull. 2000;56:444-456.

24. Karnik R, Valentin A, Ammerer HP, Hochfelner A, Donath $P$, Slany J. Outcome in patients with intracerebral hemorrhage: Predictors of survival. Wien Klin Wochenschr 2000;112:169-173.

25. Garde A, Böhmer G, Selden B, Neiman J. 100 cases of spontaneous intracerebral haematoma. Diagnosis, treatment and prognosis. Eur Neurol. 1983;22:161-172.

26. Mendelow AD, Unterberg A. Surgical treatment of intracerebral haemorrhage. Curr Opin Crit Care. 2007;13:169-174.

27. Morgenstern LB, Demchuk AM, Kim DH, Frankowski RF, Grotta JC. Rebleeding leads to poor outcome in ultraearly craniotomy for intracerebral hemorrhage. Neurology. 2001;56:1294-1299.

28. Gurol ME, St Louis EK. Treatment of cerebellar masses. Curr Treat Options Neurol. 2008;10:138-150.

29. Kaneko M, Tanaka K, Shimada T, Sato K, Uemura K. Longterm evaluation of ultra-early operation for hypertensive intracerebral hemorrhage in 100 cases. J Neurosurg. 1983;58:838-842.

30. Hemphill JC, Bonovich DC, Besmertis L, Manley GT, Johnston SC. The ICH score: a simple, reliable grading scale for intracerebral hemorrhage. Stroke. 2001;32:891-897.

31. Nakayama H, Jørgensen HS, Raaschou HO, Olsen TS. The influence of age on stroke outcome. The Copenhagen Stroke Study. Stroke. 1994;25:808-813.

32. Kanaya H. Current status of surgical therapy of hypertensive cerebral hemorrhage in Japan. Nihon Rinsho. 1982;40:2775-2782. 